\title{
BIOMECHANICAL BEHAVIOR OF DIFFERENT IMPLANT ABUTMENT MATERIALS
}

\author{
Mohamed Atif Elkholy*, Mohamed Kamel Sedeek ${ }^{* *}$, \\ Waleed Mohamed Elshahawy ${ }^{* * *}$ and Elrefaiy Sobhy Qenawy ****
}

\begin{abstract}
Purpose: to check the mechanical properties and Finite element Stress Analysis of 3 implant abutment materials.

Materials and methods : Fifteen bars (25mm length, $4 \mathrm{~mm}$. thick and $5 \mathrm{~mm}$.width) of 3 abutment materials ; High Performance polymer Hybrid abutments , Nano-Fiber reinforced Composite and Fiber strengthened Composite divided into 3 teams were exposed to Flexure Strength and Deflection tests. Fifteen implant abutments (two components abutment) coated by all ceramic crowns divided into 3 teams were exposed to Static Fracture Resistance take a look at and Finite element Stress Analysis .
\end{abstract}

Results: Flexure Strength tests mean and standard deviation of bar specimens showed vital distinction, wherever gp I, II, III were 519.29 $\pm 0.46,200.74 \pm 0.33$ and $315.43 \pm 0.59$. Also, Deflection take a look at mean and standard deviation were three. $052 \pm 0.040,0.984 \pm 0.106$, $2.028 \pm 0.027$ receptively discovered vital distinction. The comparison between fracture resistance mean and standard deviation of the tested abutment 3 groups were $642.00 \pm .5 .637,306.00 \pm 30.496$ and 514.40 \pm 12.915 respectively and discovered significant distinction. Finite part Stress Analysis of applied vertical load on the 3 abutment materials failed to have clear distinction however the smallest amount stresses created on bone with Nano-FRC abutment(16.2) followed with FRC (17.32) then BioHPP abutment (18.55).

Conclusion: Fracture strength of BioHPP abutments with ceramic crowns had the potential to resist most occlusal forces, conjointly showed higher fracture patterns than the FRC and NFRC abutments, and showed a higher stress distribution on the set, suggesting a decent mechanical behavior.

KEY WORDS: Implant abutment, Bio HPP, Nano-fiber, Fiber reinforced Composite Finite element Stress Analysis.

\footnotetext{
* Fixed Prosthodontics, Faculty of Dentistry At Tanta University

** Associate Professor, Fixed prosthodontics Depart. Faculty of Dentistry. Tanta Universty (Main Supervisor)

*** Assistant Professor, Fixed Prosthodontics Department Faculty of Dentistry Tanta University

**** Professor, Department of Chemistry, Faculty of Science. Tanta University
} 


\section{INTRODUCTION}

Currently, ceramic abutments ar fictitious out of 2 high-strength ceramic materials, a densely work high-purity alumina ceramic (A12O3) and a zirconium oxide ceramic ( $\mathrm{ZrO} 2)(1)$.Both materials have improved optical and mechanical properties and incontestable variations in their microstructure and mechanism against flaw propagation. Another step toward perfecting the outcome was gaga the event of the customizable abutment. The abutment that made from pure, extremely work aluminium oxide and incontestable considerably improved resistance compared to previous abutments ${ }^{(2,3)}$

With esthetic zone restorations, the buccal aspect of the prosthesis needs to have enough bulk of ceramic to achieve an ideal color and esthetic outcome. Additionally, associate degree aesthetically pleasing restoration needs a coronal transition depth from the implant-abutment association to the gingival margin. This maintains a correct emergence profile and masks the un-esthetic metal association.

Today the abutments ar accessible in readymade or customizable forms and might be ready within the dental laboratory either by the technician or by utilizing computer-aided design package manufacturing techniques ( $\mathrm{CAD} / \mathrm{CAM})$.The materials of preference ar densely work highpurity corundom (Al2O3) ceramic and Yttriastabilized tetragonal zirconium oxide poly-crystal ceramics(Y2O3) and alternative materials. ${ }^{(4)}$

Treatment plans ought to offer strategies for reducing stress in order that the initial loss of bone is a smaller amount seemingly to occur. ${ }^{(5)}$ There ar many techniques to enhance the biomechanical condition of the trans-osseous implant region, lowering the strain on the crystal bone. the strain are often reduced by increasing the implant surface or decreasing the biomechanical forces that will be remittent in magnitude, duration, type, direction, and application.
Another doable technique to scale back the strain at the crystal bone level is to use associate degree abutment made from a versatile material that deforms among its elastic limit, gripping a section of the load applied. The implant abutment connected to metal base to attach to the analog with screw. The implant abutments ar sometimes factory-made with high modulus of elasticity materials like metal, steel, precious alloys, or esthetic ceramics, zircon, aluminium oxide. These materials don't absorb any kind of shock of the mastication hundreds and don't assure protection to the bone-fixture interface, particularly once the aesthetic restorative material is ceramic instead of composite rosin. ${ }^{(6)}$

\section{Types of Recent Abutment Materials}

Bio-HPP (High Performance Polymer): is a possible material of modified rosin. it's a partly crystalline thermoplastic strengthened with ceramic particles to resist extreme stress, giving material is appropriate as a substructure. thus it's been used as implant abutment material in human drugs for a lot of twenty years, semi permanent expertise is ensured. This similarity with bone flexibility offers explicit blessings particularly for large-span substructures. It conjointly has some blessings as white color, are often veneered with typical veneering composites (e.g. visio-lign) giving high esthetic look and discrimination, no abrasive effect on the opposing teeth enamel. It Is metal-free, so no ion exchange in the mouth, no discoloration (7) it's smart chemical resistance, high mechanical properties, and biocompatible. it's substantially compatible with trendy imaging technologies.

For this purpose, PEEK is employed either as industrially pre-pressed pellets or in granular kind. For the pressing method, the preheated muffle (with the press plunger) is placed into the vacuum-pressing device and ironed. an alternative choice is that the milling use in CAD/CAM technologies wherever PEEK blank pressed industrially below standardized parameters like pressure, temperature and time. All 
these fabrication proces scan be appliedusing the samerawmaterial for PEEK substructure for FDPs,

Glass Fiber Reinforced Composite (FRC)is a potential material could be made of bisphenol-Aglycidyldimethacrylate (BisGMA) characterised by low modulus of elasticity. The mechanical properties of unidirectional FRCs don't seem to be solely superior to metals however conjointly on the point of that of natural bone. In several dental applications, the utilization of FRCs has inflated ${ }^{(7)}$ Attempts to use FRC as implant material for oral, orthopedic, and craniofacial applications are in practice $^{(8)}$

FRC as an implant abutment material is fairly easy to grind and regulate intra-orally while not heating the underlying bone tissue. The stuff, reinforced with fibers in fabrication of abutment parallel-oriented to its axis, permits to decrease the impulse of applied forces, this is possible due to the elastic deformation that the abutment would undergo, so increasing the time in which the load is dissipated. current analysis designed to bolster composites has shown that the addition of nano-fibers in dental resins ends up in increased wear resistance, improvement in mechanical properties and chemical change mechanics. additionally, nano-fibers have made a plain improvement within the polish ability and surface gloss of those materials similarly .

The nano-fibers used usually ar silicon dioxide and zirconium oxide nanomers $(20 \mathrm{~nm})$ and nanoclusters $(3-5 \mathrm{~nm})$ While these nano-filled hybrid materials have shown improvement in mechanical properties, they rarely show effective crack resistance nano-fibers for reinforcement of dental resins. ${ }^{(9)}$ Nano-fibers ar chemical compound or ceramic fibers having diameters move from 50$500 \mathrm{~nm}$ by virtue of which they have a high surface area and possess several fascinating properties for reinforcement of polymers. ${ }^{(10)}$

Ti-Base; is a connexion among the implant and its final restoration (abutment and prosthetic restoration) enabling $\mathrm{CAD} / \mathrm{CAM}$ custom-built solutions, highest exactness and best esthetic outcomes. Ti-Bases of variable animal tissue heights $(0.5,1.5,3 \mathrm{~mm})$ provide solutions forcases of different gingival thickness and clinical procedures. Short gingival height are going to be helpful once final restoration on the point of the implant level is desirable (esthetic zone), whereas long animal tissue height are going to be helpful in cases once a high emergence profile is needed (e.g. sub-crestal placement)

Finite Element Modeling and Stress Analysis Techniques is an accurate and efficient modeling can provide insight and understanding of the complicated nature of a dental implant that is surrounded by the jawbone. The success of modeling depends on the accuracy in simulating the geometry and surface structure of the implant, the material characteristics of the implant and jawbone, the loading and support conditions as well as the biomechanical implantjaw bone interface ${ }^{(11)}$.

The goal of this study is to evaluate the influence of reinforcing the abutment material in the ability for distribution the stress transmitted to the implant and the supporting bone by using three dimensional stress finite element analysis and evaluate fracture resistance and deflection of the experimental materials

The hypothesis of this study was that NanoFiber Reinforced Composite abutment have significant increase in the mechanical properties and good biological stress analysis in implant set and surrounding bone than the other tested groups (Bio-HPP, Nano -Fiber Reinforced Composite and Fiber Reinforced Composite).

\section{AIM OF THEWORK}

The purpose of this study was to evaluate the Bio-mechanical properties of different implant abutments materials (Bio-HPP, Nano -Fiber Reinforced Composite and Fiber Reinforced Composite) using Flexural strength, Deflection, Fracture resistance tests and 3D Finite Element Stress Analysis. 


\section{MATERIALS AND METHODS}

The three abutment materials (Bio- HPP, Nano -FRC and FRC) were studied in mechanical tests and Finite Element Stress Analysis within the surrounding structure. The flexure strength and deflection tests applied on fifteen bar specimens divided into three groups(five for each). The Fracture Strength test and Finite Element Stress Analysis of the abutment materials on the surrounding structures was applied on fifteen two parts abutment (Coronal part cemented to the Ti-base).

\section{Grouping of the specimens and applied tests:}

*Barlspecimens (15) were divided into three groupsas following :

Group I: BioHPP High Performance Polymer Hypridabutments (+vegp)(5)

Group II : Nano-glass Fiber Reinforced resin abutments (NFRC) (Experimental gp) (5)

Group III:.Glass Fiber reinforced composite GFRCabutments(-vegp)(5)

*Abutment /specimens (15) were divided into three groups as following :

Group I: BioHPP High Performance Polymer Hypridabutments (+vegp)(5)

GroupII :Nano-glass Fiber Reinforced resin abutments(NFRC)(Experimental gp) (5)

Group III..Glass Fiber reinforced composite GFRCabutments(-vegp)(5)

\section{Electrospinning Nanofiber fabrication}

Electrospun solution was brought in the following proportion $\{1: 4 \mathrm{wt} \%$ of PVA solution:TEOSin ethanol-water respectively\}. 5 gmPVA solution was dropped slowly into solution of $20 \mathrm{gm}$ TEOS in ethanol-water . the formed Fibers were dried for $12 \mathrm{hrs}$ at $70^{\circ} \mathrm{C}$ in vacuum dry oven (Vacuum drying chambers, Binder, Bohemia, North American). The needle eject nanofibers and the aluminum collector (diameter $5 \mathrm{~cm}$ ) was fixed. Nano fibers were achieved in the form of sheets. To obtain adequate size $(\leq 100 \mathrm{~nm})$, nano fibers were milled by morter and bestle. Finally, experimental composite was prepared in the proportion of $70 \mathrm{wt} \%$ nanofiller, 29 $\mathrm{wt} \%$ organic matrix and $1 \%$ light activator system. Mixing process was achieved in mixing device .

\section{Bio- HPP bar Group Fabrication:}

The Bar specimens were fabricated of BioHPP (bredent GmbH\& Co. Germany) supplied as a block and milled with the design of the dimensions of (4mm.thick, 5mm width, 25 length $\mathrm{mm}$ ) by CAD / CAM System

\section{NFRCand FRCBar specimens Fabrication}

They were fabricated from Nano-fiber reinforced composite(Nano fiber (glass fiber5\% Si02 55\%$\mathrm{A} 2 \mathrm{O} 3$ 15\%--22\%CaO, 6\% B2O3,0.5\% MgO, and $>1.0 \% \mathrm{Fe}+\mathrm{Na}+\mathrm{K}$ (Filler:, Barium, AluminumSilane 5\% ] and Fiber reinforced composite materials (Resin:BisGMA, and TEGDMA, triethylene glycol dimethacrylate) that were packed in the specimen space in a designed acrylic mold.

The acrylic mold was designed and milled with the same previous dimensions of the bar specimens. It was digitally designed and fabricated of a clear acrylic material using laser technology to be used in fabricating standardized specimens size. The mold composed of three parts (base, frame and two halves collected together with an external frame. ${ }^{(12)}$. The specimens materials NFRC and FRC packed in the mold space in increments, until the mold filled with the test materials and covered with glassslab kept backed material under a constant pressure and polymerized with Light cure device for $40 \mathrm{sec}$.

\section{Bar SpecimensTesting:}

Flexural strength and deflection test were applied by the Universal Testing Machine(INSTRON, 3600 series, USA). The bar specimens were rest flat 
on the lower fixed compartment of testing machine that has supporting rods (three points support) with a test span equal to $24 \mathrm{~mm}$. and a vertical compression load was applied at the center of the specimen at $0.5 \mathrm{~mm} / \mathrm{min}$ cross head speed. at ISO 4049:2009 ${ }^{(12)}$.

\section{Assembly the Different Abutments:}

\section{Bio-HPP Group AbutmentFabrication:}

(CAD/CAM Bio-HPP abutment):Scanning on the model of the scan body provided to the titanium base corresponding laboratory analog and screw tightly using the abutment screw provided, ensuring that no gaps, ( white scan body usingin Eos Blue or inEos X5.) The titanium base with a minimum height of $2.0 \mathrm{~mm}$. and the total height of the hybrid portion of the abutment should not exceed twice the height of the Ti Base

\section{NFRC and FRCAbutments Fabrication:}

The BioHPP abutment was duplicated using a fabricated mold with its dimensions. The mold composed of two Teflon halves collected with external metal frame. The space specimen mold was filled with experimental material(NFRC) and FRC for both group specimens. The Ti-base lubricated with separated medium and inserted in the abutment material and centralized with the long axis of the abutment by using the screw from the opposite side, then the abutment material was photo polymerized with light cure device from both sides of the mold. The polymerized abutment removed from the mold and fit to the Ti base.

Attachment the abutment to the Ti Base: The Ti Base surface cemented into abutment, by micro-air abrading fitting surface with 50 micron aluminum oxide particles. Mono-bond Plus applied for 60 seconds on the air- abraded surface. The intaglio surface of the abutment was etched with 5 percent hydrofluoric acid for 20 seconds.
The etched surface was ultrasonic cleaned in water for five minutes. MonobondPlus was applied to the intaglio surface and allowed it to react for 60 seconds. A thin coat of self-curing .Multilink Implant luting composite was applied to both components. The components were push together and the excess removed before it sets.

After the luting agent has set, the transition from titanium base to abutment was polished, the abutment and the base were screwed in the corresponding implant analogues using a hex driver. Sample assembly was mounted vertically inside metal mold with the aid of the dental surveyor in which a self-cure acrylic resin was poured vertically to the horizontal plane to mimic clinical conditions.

\section{Fabrication of the Ceramic Crown:}

The abutment samples were optically scanned so as to fabricate CADICAM premolar ceramic crown. The crowns are going to be cemented on the abutments with resin luting cement in line with manufacturer's directions.The specimens were immersed underneath water and subjected to thermal athletics 15000 cycles, $5-55^{\circ} \mathrm{C}$, and dwell time thirty seconds .In order to simulate the complicated intra-oral mechanical loading conditions, ACTA pneumatic fatigue tester (ACTA Cyclic Fatigue Tester, ACTA, Amsterdam, The Netherlands) was accustomed load the specimens.

The device consists of five loading stations every equipped with four hundred $\mathrm{N}$ pneumatic activated piston with a brief stroke distance of ten $\mathrm{cm}$. every station transmits the delivered loading force to a computerised knowledge acquisition unit employing a load cell placed underneath every specimen. flow management unit was accustomed regulate gas pressure needed activate every gas piston therefore dominant final load delivered for each specimen.

Each specimen was secured to the attachment unit of every loading station mistreatment fixation screws. The loading attachment prevented concentration of loading stresses and formation of 
cone cracks by putting a zero.5 metric linear unit powerful rubber sheet between the loading indenter and also the restorations. The antagonist was natural tooth with a load from fifty $\mathrm{N}$ to a hundred and fifty $\mathrm{N}$ and also the load was applied for 240,000 cycles to simulate 2years with a loading frequency six $\mathrm{Hz}$ to scale back testing time ( ${ }^{13)}$.

Fracture Resistance check. The samples were severally mounted on a laptop controlled materials testing machine (Model3345; InstronIndustrial Products, Norwood, MA, USA) with a load cell and also the knowledge were recorded mistreatment computer software (Instron ${ }^{\circledR}$ BluehillLite Software).

Samples were secured to the lower mounted compartment of testing machine by modification screws. Fracture test was done by compressive static load applied occlusally at the central fossa of 2 cusp slopes of the crown employing a bimetal rod with spherical tip (5.6 metric linear unit diameter) connected to the higher movable compartment of testing machine traveling at cross-head speed of $1 \mathrm{~mm} / \mathrm{min}$. with tin foil sheet in-between to attain same stress distribution and minimisation of the transmission of local force peaks.

The load at failure manifested by AN perceptible crack and confirmed by a pointy drop at loaddeflection curve recorded mistreatment laptop software (Nexygen-MT-4.6; lloyd Instruments). The load needed to fracture was recorded in Newton. The applied force as diagrammatically recorded on with failure outlined as a deviation from graphic dimensionality. when loading within the universal testing machine, the mode of failure for every check specimen were recorded by visual examination.

\section{D Finite Element Stress Analysis}

The three dimensional scanner "Premolar ceramic crown restoration", was utilized for its modeling, (Roland Active electricity device and computer) to supply cloud of points or triangulations to be cut before mistreatment in the other application. An intermediate, software was
required(Rhinocerosversion 3.0) to find out the crown pure mathematics, that was exported to finite part program as sat file format.

All model elements were meshed, by eight nodes brick element Solid 1856 that has 3 translation degrees of freedom within the world axes directions. Meshing method resulted in Brobdingnagian range of nodes, and components, that ar listed in Table1.A grid sensitivity study was performed to decide on the foremost convenient range of components (in terms of process time and results accuracy), that assured AN correct description of sharp angles and curves. Stress Analysis: set of linear static analysis was applied simulating the subsequent cases; Vertical $(200 \mathrm{~N})$ at palatal cusp slope of ceramic crowns supported by Bio HPP, Nano FRC , and FRC abutments.

Solid modeling and FEA of the strain were applied on a private computer, Intel Pentium Core to couple, processor three. $2 \mathrm{GHz}, 4.0 \mathrm{~GB}$ RAM. The meshing software was ANSYS version fourteen. $0 *$ A Finite Element Modelofa $+3.3 \mathrm{~mm} ., 10 \mathrm{~mm}$. a solid-screw implant and a solid abutment $6 \mathrm{~mm}$ tall was created, and also the implant-abutment complicated was embedded vertically within the center of a $1.5 \mathrm{~cm} \_1.5 \mathrm{~cm}$ acrylic cylinder. Static vertical of $200 \mathrm{~N}$ were applied in separate load cases.

The contact area was outlined between the implant-abutment affiliation and nonlinear finite element stress analysis was performed. The magnitude and distribution of Von Mises stresses and displacement characteristics were evaluated. In vertical loading, Von Mises stresses concentrated around the implant- abutment connection at the stem of the screw and round the implant collar that was on the point of the yield strength of titanium. Displacement values underneath each loading conditions were negligible.

So that, during a reduced-diameter a implant, vertical masses were resisted primarily by the implantabutment joint at the screw level and by the implant collar. The specimens with all elements (abutment, 
screw and analogue invested with in acrylic block) are going to be scanned for stress analysis to vertical load by 3D Finite element soft ware. Data analysis were performed in many steps, Comparison of stress results for all groups was done.

\section{RESULTS}

\section{Results of Flexural Strength Test:}

The Maximum Flexural load results of every group of the Bar specimens were checked mistreatment unidirectional multivariate analysis at the side of the Scheffé post-hoc test that applied so as to research the flexural load variations between the teams. Fig (5) shows a typical load displacement curve for every material. According to the Weibull statistics, Bio-HPP cluster Flexure load mean $(519.29 \mathrm{~N})$ showed considerably higher $(\mathrm{p}<0.001)$ characteristic (scale) than FRC $(315.43 \mathrm{~N})$ and any variations with Nano FRC (200.74N) .

During Flexure strength tests, FRC and Nano FRC Bar specimens were broken at the point of applied force on the bar. Nano FRC was quickly broken before FRC group whereas the Bar of Bio HPP sometimes showed plastic deformation, before break (Fig. 4)

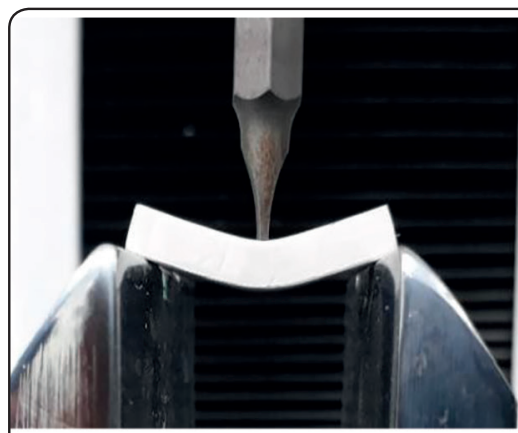

BioHPP

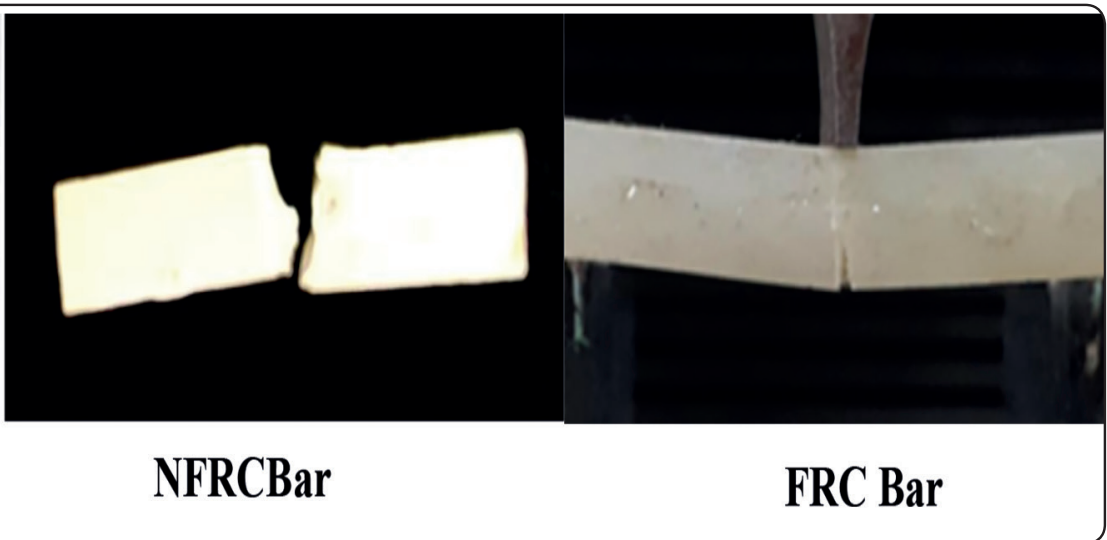

Fig. (1) Three specimens bars during Flexure and Deflection test.

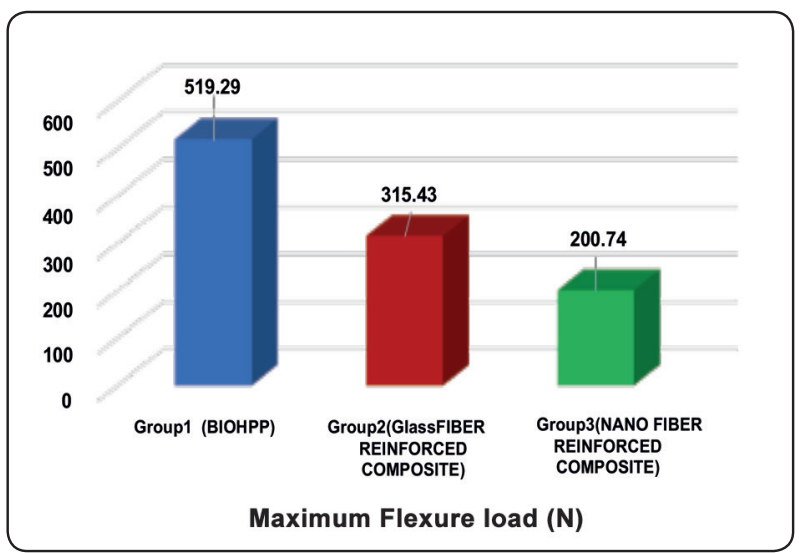

Fig. (2) Graph represent comparisons of flexure load.

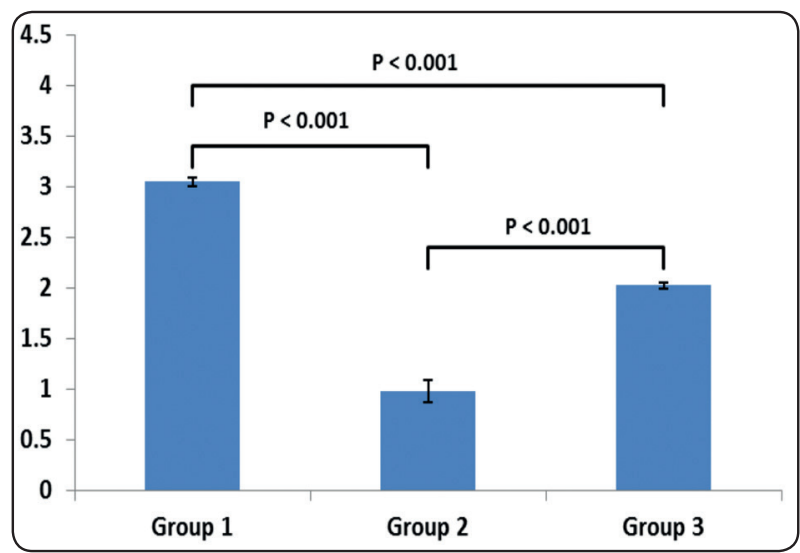

Fig. (3) Graph represents comparisons of deflection of the tested groups. 


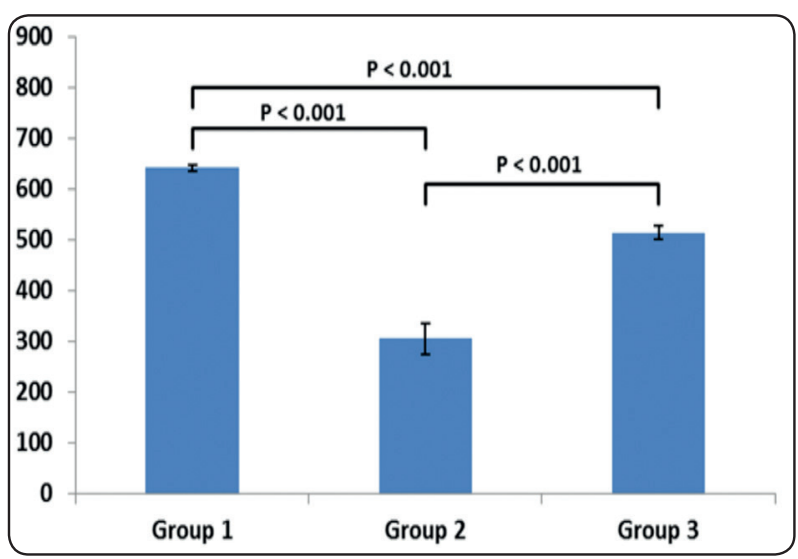

Fig. (4) Graph represents comparisons of fracture resistance

\section{Statistical Analysis of Deflection Test.}

The test reveal according to statistics, BioHPP group mean in mm. $(3.052 \pm 0.040)$ showed significantly higher $(p<0.001)$ characteristic deflection (scale) than FRC $(2.028 \pm 0.027)$ and Nano-FRC $(0.984 \pm 0.106)$ that showed a significantly lower $(p<0.001)$.

Posthoc test-Least Significant Difference (LSD) was used to compare each two means. Graph represent comparisons of deflection of the tested groups there was significance between them.

\section{Statistical Analysis of Fracture Resistance Test of The abutment}

The three groups mean and standard deviation of the rest were compared using One-Way Analysis of Variance (ANOVA) and revealed that Bio-HPP group fractured load mean $\pm \mathrm{SD}(642.00 \pm .5 .637)$ was significantly higher $(p<0.001)$ than that of NFRC (306.00 \pm 30.496$)$ and FRC $(514.40 \pm 12.91)$ (scale).

Posthoc test-Least Significant Difference (LSD) was used to compare each two groups mean (within). The fracture mode of the crown and the different abutments was clear.

\section{Finite Element Stress Analysis}

An in -depth analysis and taking into account the Von Misses stresses calculated on all parts of the model, and equivalent displacement, important conclusions can be made from this study. The Bio-HPP abutment shows a high value of stress concentration on cortical and spongy bone when compared with FRC and Nano-FRC types and there are non-significant differences between the three types. As the abutment material elasticity increases, the implant total stresses decrease. This indicated less energy absorption in the implant material with increasing abutment material elastic.

Moreover, the crown was not clearly affected by a change in the abutment material as the stress distribution, but its value reduced with decreased abutment material rigidity.

TABLE (2) Stress of vertical load the Different Abutment Materials

\begin{tabular}{|c|c|}
\hline Abutment Material & \\
\hline Bio-HPP & 18.55 \\
\hline Nano-FRC & 16.206 \\
\hline FRC & 17.3277 \\
\hline
\end{tabular}

Von Misses analysis of the vertical load on three different abutment materials used in this study showed different effects on the variables,

\section{DISCUSSION}

This study was done for evaluation of the mechanical properties of different implant abutment materials and comparing stress analysis in the surrounding bone using 3D Finite Element Analysis. The hypothesis of this study was that Nano- FRC abutment have significant increase in the mechanical properties and good biological stress analysis than the other groups.

In the present study, the specimens of all groups were artificially aged by mechanical fatigue loading and thermal cycling, which are considerably important for implant restorations, as micro 
movements are known to cause screw loosening or screw fracture, which are common failure patterns in two-piece implants. Thermo-cycling is also important to test the heat-sensitive adhesive interface between different restorative components in a moist environment. . $^{(1,2)}$

The aesthetics and bio-compatibility of the implant supported restoration material in addition to implant abutment should be evaluated during prosthetic treatment planning.

Recently improvement in high-strength aesthetic materials and fabrication techniques (CAD/ CAM) have attempted to meet the optical and biomechanical expectations in implant-supported restorations. ${ }^{(14)}$

Some of the specimens in this study showed screw loosening or debonding during the artificial aging process, which come in agreement with Finite Element Stress Analysis results that showed concentrated stress around the screw and Ti base of the abutments of the tested combinations. Also the results clarified that Bio-HPP abutment group had significantly higher fracture resistance while as a significant difference was also found between FRC group and NFRC group where $(\mathrm{p}<0.001)$.

So the results of this study did not coincide with its hypnosis that suggested the reinforcing of the composite with Nano-fiber may improve the mechanical properties of the material to be compared if used as a two parts abutment.

The physiological bite forces may range from maximum occlusal forces in the posterior area have been reported from 150 to $500 \mathrm{~N} .^{(11,15)}$ In the present study, Gp I and Gp III (BioHPP \& FRC) specimens showed failure loads over $400 \mathrm{~N}-600 \mathrm{~N}$, after thermo-mechanic alloading. While gpII (Nano-FRC) registered nearly $300 \mathrm{~N}$, that was less than average of occlusal force in posterior region.

Thereby, the first ones can resist clinical biting forces in posterior area. These results are consistent with the previous in vitro studies on different designs of ceramic abutments. ${ }^{(16,5,17)}$

The information in the literature on the use of BioHPP, Fiber reinforced composite and NanoFRC material as implant abutments with $\mathrm{Ti}$-base is limited. While the case report of using custom-made abutments $^{(18,19)}$ (BioHPP) obtained by pressing on a titanium base for a patient with single-tooth defect, and record problem with a monolithic lithium disilicate crown.

This study reported that at one and two years follow-up controls, the bone and soft tissue around the implant were stable, and it was possible to use BioHPP material as an immediate permanent implant abutment since its mechanical properties were adequate ${ }^{(20)}$. These results support and come in agree with that of the present study.

However, there is also results did not agree with the present study. The study test of titanium based zirconia abutment and an experimental BioHPP abutments subjected to fatigue testing with a chewing simulator, found that all experimental BioHPP abutments displayed screw loosening and then early failure due to screw fracture in some specimens $^{(12)}$.

Still, the study reported that titanium based BioHPP abutments are promising for the anterior and posterior region, and are suitable for use.

In another case report, Zoidis ${ }^{(21)}$ reported that BioHPP bases restored with high-strength PMMA veneers (novo.lign, Bredent) did not display any screw loosening, crown fracture, wearing or straining in the control at the end of 2 years, and it can be used as a good treatment alternative ,these results confirmed also with the present study results.

For comparison, in other study ${ }^{(13)}$. titanium abutment was selected as the control group while another group of studies used titanium based 2-piece zirconia abutments, which have proven mechanical superiority to single piece zirconia abutments. 
The results of this study showed that Group $\mathrm{Zr}(623.93 \mathrm{~N})$ and Group R PEEK $(602.93 \mathrm{~N})$ specimens have similar fracture resistances without statistically significant differences, these results also confirmed with the results of the present study.

Fracture pattern is an important as achieving the desired fracture strength values for the restorations on implants. The fracture resistance results should also be coupled with the failure type analysis. Failures that can be corrected easier than more catastrophicfailures such as an implant screw fractures, abutment fractures, deformation at implant- abutment connection site are becoming more important in selection of abutment in the restorations on implants.

The fracture occurred in the specimens in the present study, after static loading were examined with stereo microscope in line with the similar studies, and fracture pattern were described as a reparable while the custom made part of the abutment can be remade and cemented to the Tibase according to the different classifications of similar studies.

In the present study, the examinations of the fracture types with microscope revealed that E.max CAD specimens supported with Bio-HPP abutments had plastic deformation before fracture while this occurred within more time and higher load to be fractured and separated from titanium base. However FRC and Nano-FRC abutments had fractured quickly and the crown. ${ }^{(22)}$

The reported existence of other failure types, abutment and crown fractures in the FRC and NFRC abutment groups may be explained by the fact that these materials are more sensitive to thermo-cycling and phase changes in the material.

This phenomenon of the fracture was also clarified by flexure and deflection Bar specimens test where BioHPP Bars deflected and bended before fracture while the other bares FRC and NFRC fractured quickly without any deformation.

\section{CONCLUSION}

Within the limitations of this study, Bio-HPP abutments with Ti- base had significant high resistance to the occlusal load than the other abutment materials .

The all tested abutment groups had the potential to withstand maximum occlusal forces. While the stress on the restoration that supported by the NanoFRC abutment was also little analyzed through the cortical bone than in case of FRC and Bio HPP abutments.

Higher elastic modulus of the ceramic crowns associated with lower elastic modulus of the hybrid abutment shows a better stress distribution on the surrounding structure, suggesting a promising mechanical behavior

\section{RECOMMENDATIONS}

Further clinical studies that evaluate the longterm performance of polymeric abutments with Tibase are needed. These abutments can be safely recommended as esthetic alternative for the single- implant restorations or supported posterior restoration.

\section{REFERENCES}

1. Att W, Kurun S, Gerds T, Strub JR. Fracture resistance of single-tooth implant-supported all-ceramic restorations: an in vitro study. The Journal of prosthetic dentistry. 2006;95(2):111-6.

2. Keller JC, Stewart M, Roehm M, Schneider GB. Osteoporosis-like bone conditions affect osseointegration of implants. International Journal of Oral \& Maxillofacial Implants. 2004;19(5):687-94.

3. Stanford CM, Schneider GB. Functional behaviour of bone around dental implants. Gerodontology. 2004;21(2):71-7.

4. Studart AR, Filser F, Kocher P, Gauckler LJ. Fatigue of zirconia under cyclic loading in water and its implications for the design of dental bridges. Dental materials. 2007;23(1):106-14.

5. Siddiqi A, Payne AG, De Silva RK, Duncan WJ. Titanium allergy: could it affect dental implant integration? Clinical oral implants research. 2011;22(7):673-80. 
6. Keenan AV, Levenson D. Are ceramic and metal implant abutments performance similar? Evidence-based dentistry. 2010;11(3):68-9.

7. Bitter K, Kielbassa AM. Post-endodontic restorations with adhesively luted fiber-reinforced composite post systems: a review. American Journal of Dentistry. 2007;20(6):353-360.

8. Katzer A, Marquardt H, Westendorf J, Wening J, Von Foerster G. Polyetheretherketone-cytotoxicity and mutagenicity in vitro. Biomaterials. 2002; 23(8): 1749-59.

9. James R, Toti US, Laurencin CT, Kumbar SG. Electrospun nano fibrous scaffolds for engineering soft connective tissues. Methods Mol Biol. 2011;726:243-58.

10. Mohammad Al-Rabab'ah, Wala'a Hamadneh, Ismail Alsalem, AmeenKhraisat, Ashraf Abu Karaky.Use of High Performance Polymers as Dental Implant Abutments and Frameworks: A Case Series Report: J Prosthodont. 2019 Apr;28(4):365-372.

11. Pirzada T, Arvidson SA, Saquing CD, Shah SS, Khan SA. Hybrid silica-PVA nanofibers via sol-gel electrospinning. Langmuir. 2012;28(13):5834-44.

12. Neumann EAF, Villar CC, França FMG. Fracture resistance of abutment screws made of titanium, polyetheretherketone, and carbon fiberreinforced polyethere therketone. Brazilian oral research. 2014;28(1):1-5.

13. Santing HJ, Meijer HJ, Raghoebar GM, Özcan M. Fracture strength and failure mode of maxillary implant-supported provisional single crowns: a comparison of composite resin crowns fabricated directly over PEEK abutments and solid titanium abutments. Clinical implant dentistry and related research. 2012;14(6):882-9.

14. Stawarczyk B, Ender A, Trottmann A, Özcan M, Fischer $\mathrm{J}$, Hämmerle $\mathrm{CH}$. Load-bearing capacity of CAD/CAM milled polymeric three-unit fixed dental prostheses: effect of aging regimens. Clinical oral investigations. 2012;16(6):1669-77.

15. Vafiadis D, Goldstein G, Garber D, Lambrakos A, Kowalski B. Immediate implant placement of a single central incisor using a CAD/CAM crown-root form technique: provisional to final restoration. Journal of Esthetic and Restorative Dentistry. 2017;29(1):13-21.

16. Albrektsson T, Johansson C. Osteoinduction, osteoconduction and osseointegration. European spine journal. 2001;10(2):S96-S101.

17. Wu Y, Cui Y, Huynh L, Barrelet CJ, Bell DC, Lieber CM. Controlled growth and structures of molecular-scale silicon nanowires. Nano letters. 2004;4(3):433-6.

18. Al-Rabab'ah M, Macfarlane T, McCord JF. Vertical marginal and internal adaptation of all-ceramic copings made by CAD/ CAM technology. The European journal of prosthodontics and restorative dentistry. 2008;16(3):109-15.

19. Schmidlin PR, Stawarczyk B, Wieland M, Attin T, Hämmerle $\mathrm{CH}$, Fischer J. Effect of different surface pretreatments and luting materials on shear bond strength to PEEK. Dental materials. 2010;26(6):553-9.

20. Bechir ES, Bechir A, Gioga C, Manu R, Burcea A, Dascalu IT. The advantages of BioHPP polymer as superstructure material in oral implantology. Materiale Plastice. 2016; 53(3):394-8.

21. Schwitalla AD, Abou-Emara M, Zimmermann T, Spintig T, Beuer F, Lackmann J, et al. The applicability of PEEKbased abutment screws. Journal of the mechanical behavior of biomedical materials. 2016;63:244-251.

22. Lee W.T, Koak J.Y, Lim Y.J, Kim S.K, Kwon H.B, Kim M.J. 2012. Stress shielding and fatigue limits of polyetherether-ketone dental implants. J Biomed Mater Res Part B 2012:100B:1044-1052. 